\title{
Military metaphors and friendly fire
}

$\mathrm{T}$ he recent passing of the Canadian politician Jack Layton was announced in the Ottawa Citizen with the headline "Jack Layton has lost his battle with cancer." Phrases such as "fight against disease," the "clinical armamentarium" and "doctor's orders" are common in daily language and medical discourse. ${ }^{2}$ These military metaphors are not new, but have appeared in medical discourse since the 17th century, well before the advent of Pasteur. ${ }^{3}$ As a result, physicians, patients and medical students have internalized the "medicine is war" construct as a natural way of describing how we deal with illness. Although some practitioners praise this genre of figurative language for its potential to restore a sense of agency to patients, ${ }^{4}$ it is becoming increasingly clear that there are pernicious consequences.

Military metaphors reframe clinical interactions, replacing the doctorpatient relationship with a doctordisease interaction. Instead of being empowered, patients are relegated to the status of "battlefield" and become bystanders to their own care. Many feel uncomfortable with being told they have to "fight" in order to survive. Moreover, military metaphors are "inherently masculine, power-based, paternalistic and violent."4

When Lance Armstrong received the news that he had cancer and his oncologist said he would have to "kill" Armstrong and "hit him again and again with chemotherapy," Armstrong's response was to flee and seek clinical counsel elsewhere. ${ }^{4}$

Many sources suggest that patients do not consider the war metaphor to be an appropriate approach to their care. In her article, "Expressive metaphors in cancer narratives," Carola Skott concludes that patients conceive of illness in their own ways. For example, some patients see cancer as "a thing in the air" as opposed to being "invaded by a killer." She suggests that "metaphors in

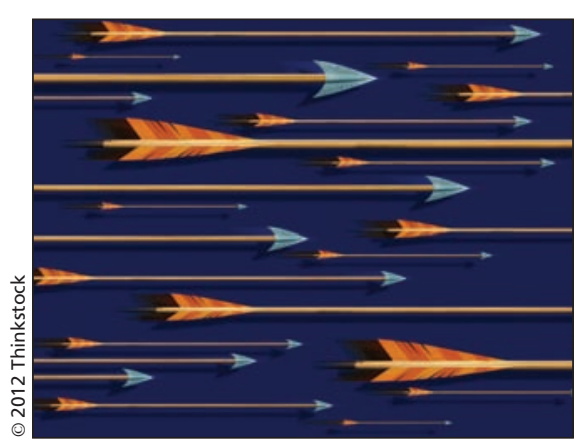

illness narratives make experience intelligible and connect individual illness to collective experience." ${ }^{5}$ When medicine is seen as war, patients may believe that becoming healthy is only a matter of "fighting" hard enough. But, who loses when disease "triumphs"? As the late Robert Buckman noted, "the idea that he [Jack Layton] was waging a battle which he lost demeans him." ${ }^{\prime \prime}$ Too often, physicians add insult to injury by making patients responsible when treatments fail.

In his book, Rehabilitations and Other Essays, C.S. Lewis describes what can go wrong when a "master" uses a metaphor to explain a concept to a "pupil." The "master" understands the relationship between the literal and figurative meanings, while the "pupil" hears "the unique expression of a meaning" which immediately places a constraint on his thinking. Thus, when physicians use metaphors to explain concepts to patients, the latter are "at the mercy of the metaphor" as it "dominates completely the thought of the recipient whose truth cannot rise above the truth of the original metaphor."

The military metaphor is conceptually weak and often fails to provide a meaningful or useful description of the patient's reality. Characterizing disease as the enemy can be fraught with contradictions. For example, what is the "target" to be "fought against" or "eradicated" in mental illness? ${ }^{8}$ Whose cells are "killed" when patients receive chemotherapy? More importantly, such language interferes with a reflective approach to decision-making. ${ }^{8}$ At a time when patients and families want to be part of a thoughtful discussion about treatments, the phrase, "don't worry, we'll fight this together" is hardly enlightening.

As Lakoff and Johnson define it, "the essence of metaphor is understanding and experiencing one kind of thing in terms of another." Are there any constructive alternatives available to the thoughtful clinician? One need only look at the language of a medical school physiology class where the notion of "homeostasis" is fundamental. The ideas elaborated by the physiologist, Walter Cannon, provide a framework to conceive of health and disease in terms of balance and its lossillness as "dystasis," as it were. Other alternatives are the notions of flow and blockage in the East Asian tradition, or of medicine as a "journey"10 or "collaborative exploration."

A recent oncology article underscores the importance of figurative language in medicine: "metaphors don't merely describe similarities; they create them." ${ }_{11}$ This notion that language shapes behaviour is an old idea in linguistics $^{12}$ and has important implications in the clinical setting. Considering how pervasive and undermining military metaphors are, it behooves any practitioner interested in forming a healing relationship with a patient to think carefully about the power of words. To quote Tony Judt, "If words fall into disrepair, what will substitute? They are all we have."13

\section{Douglas Slobod}

Second year medical student

Abraham Fuks MDCM

Professor of medicine

Faculty of Medicine

McGill University

Montréal, Que.

For references, see Appendix 1, available at www.cmaj.ca/lookup/suppl/doi:10.1503/cmaj $.111438 /-/ D C 1$. 